Tropical Journal of Pharmaceutical Research June 2020; 19 (6): 1249-1254

ISSN: $1596-5996$ (print); 1596-9827 (electronic)

(C) Pharmacotherapy Group, Faculty of Pharmacy, University of Benin, Benin City, 300001 Nigeria.

\title{
Anti-diabetic effect of a monoamine oxidase inhibitor (tranylcypromine) in rats with poorly-controlled blood glucose levels: A potential and novel therapeutic option for diabetes
}

\author{
Jingying Qiu ${ }^{1}$, Chengjiang $\mathrm{Li}^{2}$, Zhichun Dong ${ }^{1}$, Jing Wang ${ }^{1 *}$ \\ ${ }^{1}$ Department of Endocrinology, Shengzhou People's Hospital (The First Affiliated Hospital of Zhejiang University Shengzhou \\ Branch), Zhejiang, Shengzhou 312400, '2Department of Endocrinology, The First Affiliated Hospital Zhejiang University, \\ Zhejiang, Hangzhou 310003, China
}

*For correspondence: Email: wjing0525@163.com; Tel/Fax: 0086-0575-83338312

\begin{abstract}
Purpose: To determine the anti-diabetic effect of a monoamine oxidase inhibitor (tranylcypromine) in sulphonyl urea-refractory rats with poorly-controlled blood glucose levels.

Methods: Alloxan-induced diabetic Wistar rats were assigned to two groups (30 rats/group). One group received glibenclamide at a dose of $0.6 \mathrm{mg} / \mathrm{kg}$, while the other group was given monoamine oxidase inhibitor (tranylcypromine) at a dose of $5 \mathrm{mg} /$ day. The two groups were treated for 2 weeks. Blood samples were collected at baseline (before treatment) and at the end of treatment for determination of plasma glucose (fasting and fed), hemoglobin A1c, lipid profiles (serum total cholesterol, very-lowdensity lipoprotein, low-density lipoprotein, high-density lipoprotein and triglycerides); oxidative stress parameters (anti-oxidant enzymes), insulin levels, and some hepatic enzymes of glucose metabolism. Results: Monoamine oxidase inhibitor treatment resulted in significant decrease in the levels of blood glucose, HbA1c, and lipid levels from baseline, relative to glibenclamide $(p<0.05)$. Greater improvements in oxidative stress biomarkers (glutathione and superoxide dismutase), insulin levels and hepatic enzymes of glucose metabolism were observed in monoamine oxidase inhibitor group than in glibenclamide group $(p<0.05)$. Oxidative stress was significantly inhibited by monoamine oxidase inhibitor via increases in glutathione (GSH) level and superoxide dismutase (SOD) activity, when compared to glibenclamide $(p<0.05)$.

Conclusion: These results suggest that monoamine oxidase inhibitor may be a better treatment option for diabetes than glibenclamide.
\end{abstract}

Keywords: Diabetes, Monoamine oxidase inhibitor, Glibenclamide, Sulphonyl urea, Poorly-controlled blood glucose

This is an Open Access article that uses a fund-ing model which does not charge readers or their institutions for access and distributed under the terms of the Creative Commons Attribution License (http://creativecommons.org/licenses/by/4.0) and the Budapest Open Access Initiative (http://www.budapestopenaccessinitiative.org/read), which permit unrestricted use, distribution, and reproduction in any medium, provided the original work is properly credited.

Tropical Journal of Pharmaceutical Research is indexed by Science Citation Index (SciSearch), Scopus, International Pharmaceutical Abstract, Chemical Abstracts, Embase, Index Copernicus, EBSCO, African Index Medicus, JournalSeek, Journal Citation Reports/Science Edition, Directory of Open Access Journals (DOAJ), African Journal Online, Bioline International, Open-J-Gate and Pharmacy Abstracts

\section{INTRODUCTION}

Diabetes mellitus (DM) is one of the most common forms of metabolic disorder which is characterized by increased blood sugar levels in the fasted and fed states, decreased levels of insulin, insulin sensitivity/resistance, and comparative absence of insulin [1-3]. The 
incidence of Type 2 DM (T2DM) and its associated financial burden have been increasing at alarming rates [4]. There are several modalities for management of T2DM, the most common of which involves the use of metformin and sulfonylurea class of drugs [5-8].

Metformin is usually used for overweight or obese patients. It is safe, since it lowers blood sugar level without causing hypoglycemia for obese patients with sedentary lifestyles. Metformin belongs to biguanide class of antidiabetic drugs which significantly decrease hepatic turnover of glucose. The sulphonyl urea class of drugs is most commonly used for patients who lack insulin sensitivity, and patients with decreased level of insulin release from B cells of the pancreas [8-10].

Patients who fail to respond to monotherapy of either metformin or sulphonyl urea are subjected to combination therapy using metformin and sulphonyl urea class of drugs, in addition to lifestyle modifications, for effective glycemic control. Currently, other classes of anti-diabetic drugs are in use. These include alphaglucosidase inhibitors which lower postprandial glucose levels, thiazolidinedione which increase insulin sensitivity, thereby preventing resistance to oral treatments, and GLP-1 receptor agonists which improve blood glucose levels, with less risk of weight gain and hypoglycemia. Insulin therapy (via injection) is recommended for T2DM patients who fail to respond to oral anti-diabetic therapy [11-15].

Each treatment has its own limitations, either in terms of safety concerns or convenience. Effective management of diabetes mellitus requires different treatment modalities. Multiple drug combinations have been advocated, although these may cause additional safety concerns due to multiple drug use, apart from the problem of extra financial burden [5-9]. The agents that improve glycemic control along with lowering of blood lipid levels and blood pressure, could also significantly improve morbidity and mortality. Thus, there is need for effective therapy that has fewer side effects, with balanced risk-benefit to T2DM patients, while effectively ameliorating diabetes-induced complications [16-19].

Recently, the blood sugar-reducing effect of monoamine oxidase inhibitor was observed, indicating its anti-hyperglycemic property. It has been reported that monoamine oxidase produced positive effects in patients with type 1 diabetes $[14,15]$. However, the effect of monoamine oxidase inhibitor on sulfonylurea-refractory rats with poorly controlled blood glucose level has not been investigated. Moreover, little is known about the effect of monoamine oxidase inhibitor on $\mathrm{HbA} 1 \mathrm{c}$, lipid profiles, oxidative stress biomarkers, hepatic enzymes of glucose metabolism, and insulin levels. Thus, the present study was designed to determine the effect of monoamine oxidase inhibitor on sulfonylurearefractory rats with poorly-controlled blood glucose levels.

\section{EXPERIMENTAL}

A total of 60 male adult Wistar rats weighing 200 to $250 \mathrm{~g}$ were equally allocated 2 groups. One group was given glibenclamide at a dose of 0.6 $\mathrm{mg} / \mathrm{kg}$, while the other group received monoamine oxidase inhibitor (tranylcypromine) at a dose of $5 \mathrm{mg} /$ day. All experiments were performed after prior ethical approvals from the Animal Committee of Zhejiang University (approval no. EC-A-ZU/184/19DZ-2019). The CPCSEA guidelines were followed for animal care in all the study-related procedures [20]. The rats were kept in quarantined cages with 12-h day/12-h night light cycle, and were allowed access to feed and water as and when required. The study protocol used in this investigation was approved by the Animal Ethics Committee of the Zhejiang University Shengzhou Branch), Zhejiang. The rats were treated for 2 weeks (14 days).

Blood samples were collected at baseline (before treatment) and at the end of treatment. The blood samples were collected from the rats via the saphenous vein using a 20-guage needle. Plasma levels of glucose and $\mathrm{HbA} 1 \mathrm{c}$ were determined using auto-analyzer. Moreover, changes in lipid profiles (TC, VLDL, LDL, HDL and TGs); oxidative stress biomarkers (antioxidant enzymes), and insulin levels were determined. The activities of hepatic enzymes of glucose metabolism, as well as liver and kidney biomarkers were also assayed. Diabetes was induced in fasted rats via intraperitoneal administration of alloxan at a dose of $70 \mathrm{mg} / \mathrm{kg}$. Alloxan-induced diabetes was tested after 24-72 $\mathrm{h}$ of alloxan administration. Each rat was sacrificed by decapitation, and blood sample was collected from the saphenous vein, centrifuged and kept at $-80{ }^{\circ} \mathrm{C}$ prior to assays. Body weight was also recorded before and after treatment.

All blood samples were promptly centrifuged for at least $10 \mathrm{~min}$ at $1500 \mathrm{~g}$ at $4{ }^{\circ} \mathrm{C}$. The serum samples were separated and kept frozen at -80 ${ }^{\circ} \mathrm{C}$ until used. Laboratory investigations were carried out at the same laboratory using an autoanalyzer. Glucose levels were estimated using 
glucose oxidase enzymatic kits. Serum total cholesterol was estimated using aminoantipyrine enzymatic (AAE) method. In addition, HDL level was estimated using AAE method after precipitation of LDL. Triglycerides (TGs) were estimated using the glycerol-3-phosphate AAE method. Serum LDL-cholesterol level was calculated with the Friedewald method. Hemoglobin A1C (HbA1c) was measured using commercial kit. Insulin level was measured using ELISA kits. The liver of each rat was excised and homogenized in buffer. The homogenate was centrifuged for at least $1 \mathrm{~h}$ at $100,000 \mathrm{~g}$, and the supernatant was used for the assay of glucose-6phosphatase, malic enzyme and phosphoenolpyruvate carboxykinase. The antioxidants i.e. reduced glutathione (GSH), and SOD was measured using nitroblue tetrazolium (NBT) test, spectrophotometrically at $415 \mathrm{~nm}$. All assays were carried out in the same laboratory in order to avoid inter-laboratory variations in results.

\section{Statistical analysis}

No formal sample size was calculated since the present investigation was a preliminary one. However, at least 15 rats in each group were planned to include in this study. Comparison of quantitative and qualitative data was done using Student $t$-test or Mann-Whitney test or Chisquare or Fisher exact test. Non-normal data were analyzed using non-parametric test; whereas normal data were analyzed using parametric test. Values are expressed as Mean \pm $\mathrm{SD}$, otherwise stated. Statistical analysis was performed using SPSS 25.0 software. Statistical significance of difference was assumed at $p$ $<0.05$.

\section{RESULTS}

At baseline, there were no significant differences between the two groups with respect to gender, bodyweight, $\mathrm{HbA1c}$, lipid profiles (serum TC, VLDL, LDL, HDL and TGs), and plasma blood glucose levels (fasting and $2 \mathrm{~h}$ postprandial). These results are shown in Table 1.

The baseline clinical characteristics were comparable between both treatment groups. After2 weeks of treatment, there were marked decreases in levels of blood glucose, HbA1c and lipids in both groups $(p<0.05)$. However, the reductions in levels of blood glucose, $\mathrm{HbA} 1 \mathrm{c}$ and lipids were significant greater in the tranylcypromine group than in glibenclamide group after 2 weeks of treatment $(p<0.05$, Table 2).
Table 1: Baseline clinical characteristics

\begin{tabular}{llll}
\hline Characteristic & $\begin{array}{l}\text { Test } \\
(\mathbf{n}=15)\end{array}$ & $\begin{array}{l}\text { Control } \\
(\mathbf{n = 1 5})\end{array}$ & $\boldsymbol{P}$ \\
\hline Sex, M/F (\%) & $64 / 36$ & $61 / 39$ & $>0.05$ \\
Weight (g) & $215 \pm 12.4$ & $238.8 \pm 4.6$ & $>0.05$ \\
HbA1c $(\%)$ & 7.8 & 8.1 & $>0.05$ \\
HbA1c $(\mathrm{mol} / \mathrm{mol})$ & $1.5 \pm 0.7$ & $1.4 \pm 0.9$ & $>0.05$ \\
FBG $(\mathrm{mmol} / \mathrm{L})$ & $1.5 \pm 0.7$ & $1.4 \pm 0.9$ & $>0.05$ \\
FBG $(\mathrm{mg} / \mathrm{dL})$ & $1.9 \pm 0.3$ & $1.7 \pm 0.5$ & $>0.05$ \\
\hline
\end{tabular}

Values are expressed as mean \pm SD, otherwise stated. Un-paired $t$ test for numerical data, Fisher exact test for categorical data. (Test: tranylcypromine (5 mg/day); Control: glibenclamide $(0.6 \mathrm{mg} / \mathrm{kg})$

Table 1: Blood glucose levels (in fasted and fed states), HbA1c, lipid profiles (serum TC, VLDL, LDL, $\mathrm{HDL}$ and TGs) after 2 weeks of drug treatments

\begin{tabular}{|c|c|c|c|}
\hline Parameter & $\begin{array}{c}\text { Test } \\
(n=15)\end{array}$ & $\begin{array}{c}\text { Control } \\
(n=15)\end{array}$ & $\begin{array}{c}P- \\
\text { value }\end{array}$ \\
\hline \multicolumn{4}{|c|}{ Blood glucose levels (mg/dL) } \\
\hline Fasting & $113.3 \pm 3.13$ & $136.2 \pm 2.11$ & $<0.05$ \\
\hline Fed & $165.2 \pm 7.16$ & $197.1 \pm 6.13$ & $<0.05$ \\
\hline HbA1c (\%) & $6.2 \pm 0.21$ & $7.7 \pm 0.74$ & $<0.05$ \\
\hline \multicolumn{4}{|c|}{ Lipid profiles (mg/dL) } \\
\hline Serum TC & $206.2 \pm 3.14$ & $236.5 \pm 3.02$ & $<0.05$ \\
\hline VLDL & $153.0 \pm 4.13$ & $172.9 \pm 5.21$ & $<0.05$ \\
\hline$L D L$ & $132.3 \pm 4.5$ & $141.5 \pm 3.14$ & $<0.05$ \\
\hline$H D L$ & $41.3 \pm 3.3$ & $30.2 \pm 1.13$ & $<0.05$ \\
\hline
\end{tabular}

Values are expressed as Mean \pm SD, otherwise stated. $P$-value was determined with un-paired $t$-test. Test: tranylcypromine (5 mg/day); Control: glibenclamide $(0.6 \mathrm{mg} / \mathrm{kg})$

At baseline (before drug treatment), levels of oxidative stress biomarkers (GSH and SOD), and insulin and hepatic enzymes of glucose metabolism were comparable between the two treatment groups. However, there were steady improvements in oxidative stress, insulin level and hepatic glucose metabolic enzymes over a period of 2 weeks in both groups. Within-group comparison showed that both treatments were effective. However, between-group comparison revealed that improvement was significantly higher in the tranylcypromine group than in glibenclamide group $(p<0.005)$. These results are presented in Table 3.

As shown in Figure 1, treatment with monoamine oxidase inhibitor resulted in improved levels of hepatic enzymes. At baseline (before drug treatment), body weights were comparable between the two treatment groups. After 2 weeks of treatment, body weight was reduced from baseline in both groups. However, reduction in bodyweight was statistically higher in the tranylcypromine group $(-112 \mathrm{~g})$ than in glibenclamide group $(-57 \mathrm{~g} ; \mathrm{p}<0.05)$. Moreover, incidence of hypoglycemia was higher in glibenclamide group than in tranylcypromine group. This indicates that rats treated with MAO 
inhibitor were less likely to have episodes of hypoglycemia than those treated with glibenclamide.

The effects of both treatments on enzyme markers of liver and kidney functions were comparable, as shown in Table 4.

\section{DISCUSSION}

The present study is the first investigation designed to determine the effect of monoamine oxidase inhibitor (MAOI) on sulfonylurearefractory rats with poorly controlled blood glucose level. Little was hitherto known about the effect of monoamine oxidase inhibitor on $\mathrm{HbA} 1 \mathrm{c}$, lipid profiles, oxidative stress, insulin level and hepatic enzymes of glucose metabolism.

Table 3: Comparison of levels of oxidative stress parameters, insulin and hepatic enzymes of glucose metabolism after 2 weeks of drug treatments

\begin{tabular}{|c|c|c|c|}
\hline Parameter & $\begin{array}{c}\text { Test } \\
(n=15)\end{array}$ & $\begin{array}{l}\text { Control } \\
(n=15)\end{array}$ & $\boldsymbol{P}$ \\
\hline \multicolumn{4}{|c|}{ Levels of oxidative stress biomarkers } \\
\hline Glutathione & $113.3 \pm 3.13$ & $\begin{array}{l}136.2 \pm 2.1 \\
1\end{array}$ & $\begin{array}{l}<0.0 \\
5\end{array}$ \\
\hline $\mathrm{SOD}(\mathrm{U} / \mathrm{ml})$ & $165.2 \pm 7.16$ & $\begin{array}{l}197.1 \pm 6.1 \\
3\end{array}$ & $\begin{array}{l}<0.0 \\
5\end{array}$ \\
\hline $\begin{array}{l}\text { Insulin } \\
\text { level(ng/mL) }\end{array}$ & $0.5 \pm 0.1$ & $0.2 \pm 0.2$ & $\begin{array}{l}<0.0 \\
5\end{array}$ \\
\hline \multicolumn{4}{|c|}{ Hepatic glucose metabolic enzymes (U/G tissue) } \\
\hline $\begin{array}{l}\text { Glucose } 6 \\
\text { phosphatase } \\
\text { dehydrogenase }\end{array}$ & $\begin{array}{l}5.3 \pm 0.2 \\
4\end{array}$ & $3.5 \pm 0.32$ & $\begin{array}{l}<0.0 \\
5\end{array}$ \\
\hline Malic enzyme & $\begin{array}{l}2.5 \pm 0.1 \\
3\end{array}$ & $1.9 \pm 0.20$ & $\begin{array}{l}<0.0 \\
5\end{array}$ \\
\hline $\begin{array}{l}\text { Phosphoenolpyruvat } \\
\text { e carboxykinase }\end{array}$ & $\begin{array}{l}43.3 \pm 4 \\
5\end{array}$ & $56.5 \pm 4.14$ & $\begin{array}{l}<0.0 \\
5\end{array}$ \\
\hline
\end{tabular}

Data are expressed as mean $\pm \mathrm{SD}$, otherwise stated. $P$-value was determined using Unpaired $t$ test. Test: tranylcypromine (5 mg/day); Control: Glibenclamide $(0.6 \mathrm{mg} / \mathrm{kg})$

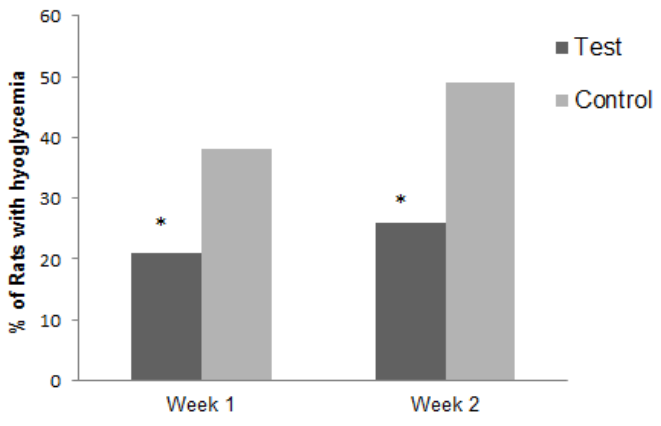

Figure 1: Percentage of rats with hypoglycemia in the two groups after treatment; ${ }^{*} p<0.05$, using Fisher exact test. Test: tranylcypromine $5 \mathrm{mg} /$ day; Control: Glibenclamide $(0.6 \mathrm{mg} / \mathrm{kg})$
Table 4: Blood levels of liver and kidney function biomarkers after 2 weeks of drug treatments

\begin{tabular}{lccc}
\hline Parameter & $\begin{array}{c}\text { Test } \\
(\mathbf{n}=\mathbf{1 5})\end{array}$ & $\begin{array}{c}\text { Control } \\
(\mathbf{n = 1 5})\end{array}$ & $\begin{array}{c}\boldsymbol{P} \text { - } \\
\text { value }\end{array}$ \\
\hline ALT & $123.1 \pm 8.3$ & $125.3 \pm 6.1$ & $>0.05$ \\
AST & $89.2 \pm 2.16$ & $93.3 \pm 1.34$ & $>0.05$ \\
ALP & $230.1 \pm 12.1$ & $237.2 \pm 2.3$ & $>0.05$ \\
Creatinine & $0.8 \pm 0.14$ & $0.7 \pm 0.21$ & $>0.05$ \\
Gamma- & $12.2 \pm 2.13$ & $13.4 \pm 3.42$ & $>0.05$ \\
Glutamyl & & & \\
$\begin{array}{l}\text { Transferase, } \\
\text { (U/L) }\end{array}$ & & & \\
$\begin{array}{l}\text { Total protein } \\
\text { (g/dlL) }\end{array}$ & $4.9 .3 \pm 1.5$ & $4.7 \pm 1.8$ & $>0.05$ \\
\hline Values are & & & \\
\hline
\end{tabular}

Values are expressed as Mean \pm SD, otherwise stated. $P$ was determined using Unpaired $t$ test. test: tranylcypromine (5 mg/day); control: Glibenclamide (0.6 mg/kg)

Thus, the present study determined the effect of a monoamine oxidase inhibitor on these parameters. There is a need for alternative therapy with favorable risk-benefit ratio for T2DM patients. In the present study, the two study drugs were effective in decreasing levels of blood glucose, $\mathrm{HbA} 1 \mathrm{c}$ and lipid. However, reductions in levels of blood glucose, $\mathrm{HbA} 1 \mathrm{c}$, lipids were significantly higher in rats treated with tranylcypromine than in the glibenclamide group after 2 weeks of treatment.

A similar trend was observed with respect to levels of oxidative stress biomarkers, insulin and hepatic enzymes of glucose metabolism. However, there were significantly higher improvements in levels of these parameters in tranylcypromine-treated rats than in the glibenclamide-treated group. Moreover, monoamine oxidase inhibitor treatment preserved the activities of hepatic enzymes and protected the integrity of pancreatic $\beta$-cells. Indeed, it is known that treatment with monoamine oxidase inhibitor results in the most protective effect in rodent models of diabetes [21-23].

The results of this study are consistent with those obtained in previous studies on the efficacy of MAO inhibitor in reducing blood glucose level. Earlier studies on MAOI reported that monoamine oxidase inhibitor reduced blood glucose levels, indicating its anti-hyperglycemic effects [14-18]. The positive effect of monoamine oxidase has been observed in patients with type 1 diabetes. However, the earlier studies focused only on the effect of MAOI on blood glucose [14, 15]. In contrast, the present study determined the effect of MAO on several parameters, including glycemic control (HbA1c), lipid profiles, oxidative stress biomarkers, insulin level and some hepatic enzymes of glucose metabolism (glucose-6-

Trop J Pharm Res, June 2020; 19(6): 1252 
phosphatase dehydrogenase, malic enzyme, and phosphoenolpyruvate carboxykinase).

Moreover, this study addressed two main safety concerns of anti-diabetic drugs i.e. weight gain and hypoglycemia. The incidence of weight gain and hypoglycemia were significantly lower in MAOI group than in glibenclamide group. Moreover, tranylcypromine produced greater improvement in body weight than glibenclamide, and the incidence of hypoglycemia was higher in glibenclamide group than in tranylcypromine group. This indicates that rats treated with MAO inhibitor are less likely to have episodes of hypoglycemia than those given glibenclamide. The findings in the present study indicate that MAOI is an effective treatment option for T2DM: it showed low risk of weight gain and hypoglycemia, and greater anti-hyperglycemic efficacy than glibenclamide. Although the levels of liver and kidney function biomarkers were higher in tranylcypromine group than in glibenclamide group, the difference was not statistically significant.

The finding of present study may not translate to direct clinical application, due to its pre-clinical nature. Thus, a randomized clinical trial, with appropriate sample size needs to be designed to confirm the findings prior to clinical application.

\section{CONCLUSION}

The results of this study suggest that treatment with MAOI is effective in correcting diabetesassociated metabolic imbalance. The results strongly indicate that MAOI may be a better alternative therapy for diabetes than glibenclamide.

\section{DECLARATIONS}

\section{Conflict of interest}

No conflict of interest is associated with this work.

\section{Contribution of authors}

We declare that this work was done by the authors named in this article and all liabilities pertaining to claims relating to the content of this article will be borne by the authors.

\section{Open Access}

This is an Open Access article that uses a funding model which does not charge readers or their institutions for access and distributed under the terms of the Creative Commons Attribution License (http://creativecommons.org/licenses/by/ 4.0) and the Budapest Open Access Initiative (http://www.budapestopenaccessinitiative.org/rea d), which permit unrestricted use, distribution, and reproduction in any medium, provided the original work is properly credited.

\section{REFERENCES}

1. American Diabetes Association. Diagnosis and classification of diabetes mellitus. Diabetes Care 2010; 33: S62-S69.

2. Wild S, Roglic G, Green A, Sicree R, King H. Global prevalence of diabetes: estimates for the year 2000 and projections for 2030. Diabetes Care 2004; 27(5): 10471053.

3. Yim S, Malhotra A, Veves A. Antioxidants and CVD in diabetes: where do we stand now. Curr Diab Rep 2007; 7(1): 8-13.

4. Whiting DR, Guariguata L, Weil C, Shaw J.IDF diabetes atlas: global estimates of the prevalence of diabetes for 2011 and 2030.Diabetes Res Clin Pract 2011; 94(3): 311-321.

5. Savu O, Ionescu-Tirgoviste C, Atanasiu V, Gaman L, Papacocea R, Stoian I. Increase in total antioxidant capacity of plasma despite high levels of oxidative stress in uncomplicated type 2 diabetes mellitus. $J$ Int Med Res 2012; 40(2): 709-716.

6. Giacco F, Brownlee M. Oxidative stress and diabetic complications. Circ Res 2010; 107(9): 1058-1070.

7. de Sereday MS, Gonzalez C, Giorgini D, De Loredo L. Prevalence of diabetes, obesity, hypertension and hyperlipidemia in the central area of Argentina. Diabetes Metab 2004; 30(4): 335-339.

8. Sharma SB, Nasir A, Prabhu KM, Murthy PS, Dev G. Hypoglycaemic and hypolipidemic effect of ethanolic extract of seeds of Eugenia jambolana in alloxaninduced diabetic rabbits. J Ethnopharmacol 2003; 85: 201-206.

9. Ceriello A. Postprandial hyperglycemia and diabetes complications: is it time to treat? Diabetes 2005; 54(1): 1-7.

10. Cersosimo E, Solis-Herrera C, Trautmann ME, Malloy J, Triplitt CL. Assessment of pancreatic $\beta$-cell function: review of methods and clinical applications. Curr Diabetes Rev 2014; 10(1): 2-42.

11. Go HK, Rahman MM, Kim GB. Antidiabetic Effects of Yam (Dioscorea batatas) and Its Active Constituent, Allantoin, in a Rat Model of Streptozotocin-Induced Diabetes. Nutrients 2015; 7(10): 8532-8544.

12. Gupta D, Raju J, Prakash J, Baquer NZ. Change in the lipid profile, lipogenic and related enzymes in the livers of experimental diabetic rats: effect of insulin and vanadate. Diabetes Res Clin Pract 1999; 46(1): 1-7.

13. McLellan AC, Thornalley PJ, Benn J, Sonksen PH. Glyoxalase system in clinical diabetes mellitus and 
correlation with diabetic complications. Clin Sci (Lond) 1994; 87(1): 21-29.

14. Emory H, Mizrahi N. Glycaemic control by monoamine oxidase inhibition in a patient with type 1 diabetes. Diab Vasc Dis Res 2017; 14(2): 163-165.

15. Adnitt PI. Hypoglycemic action of monoamineoxidase inhibitors (MAOI'S). Diabetes. 1968; 17(10): 628-633.

16. Rolo AP, Palmeira CM. Diabetes and mitochondrial function: role of hyperglycemia and oxidative stress. Toxicol Appl Pharmacol. 2006; 212(2): 167-178.

17. Zak B, Epstein E, Baginski ES. Determination of liver microsomal glucose-6-phosphatase. Ann Clin Lab Sci 1977; 7(2): 169-177.

18. Tahrani AA, Piya MK, Kennedy A, Barnett AH. Glycaemic control in type 2 diabetes: targets and new therapies. Pharmacol Ther. 2010; 125(2):328-361.

19. Vidal-Puig A, O'Rahilly S. Metabolism. Controlling the glucose factory. Nature 2001; 413(6852): 125-126.
20. CPCSEA Guidelines for laboratory animal facility. Committee for the Purpose of Control and Supervision on Experiments on Animals. Indian Journal of Pharmacology 2003; 35: 257-274

21. Ramesh B, Saralakumari D. Antihyperglycemic, hypolipidemic and antioxidant activities of ethanolic extract of Commiphor amukul gum resin in fructose-fed male Wistar rats. J Physiol Biochem 2012; 68(4): 573582.

22. Robertson RP, Tanaka Y, Takahashi H, Tran PO, Harmon JS. Prevention of oxidative stress by adenoviral overexpression of glutathione-related enzymes in pancreatic islets. Ann N Y Acad Sci 2005; 1043: 513520.

23. Zhou B, Zou H, Xu G. Clinical Utility of Serum Cystatin C in Predicting Diabetic Nephropathy Among Patients with Diabetes Mellitus: a Meta-Analysis. Kidney Blood Press Res 2016; 41(6): 919-928. 